\title{
Application of Polymer Based Nanocomposites for Water Shutoff-A Review
}

\author{
Velima Obino *D and Upendra Yadav (D)
}

Citation: Obino, V.; Yadav, U. Application of Polymer Based Nanocomposites for Water Shutoff-A Review. Fuels 2021, 2, 304-322. https://doi.org/ $10.3390 /$ fuels2030018

Academic Editor: Badie Morsi

Received: 14 April 2021

Accepted: 23 July 2021

Published: 18 August 2021

Publisher's Note: MDPI stays neutral with regard to jurisdictional claims in published maps and institutional affiliations.

Copyright: (c) 2021 by the authors. Licensee MDPI, Basel, Switzerland. This article is an open access article distributed under the terms and conditions of the Creative Commons Attribution (CC BY) license (https:// creativecommons.org/licenses/by/ $4.0 /)$.
Department of Petroleum Engineering and Earth Sciences, University of Petroleum and Energy Studies, Dehradun 248007, India; usyadav@ddn.upes.ac.in

* Correspondence: velima@uonbi.ac.ke or kerubovelmah@gmail.com; Tel.: +254-710187109

\begin{abstract}
One highly undesirable characteristic of mature assets that inhibits oil recovery is high water production. Polymer gel treatment is a popular conformance improvement technique applied in this regard due to its cost effectiveness and proved efficiency. Despite this popularity, optimum performance of polymer hydrogels in water shut off is inhibited by excessive aggregation, difficulty in controlling gelation, and their instability at high temperature and high salinity reservoir conditions. To address these shortcomings, research on the application of nanoparticles (NPs) in polymer hydrogels to manage thermal stability and salinity sensitivity has significantly increased in the recent past. By incorporating metal-based NPs, silica or graphene at nanoscale; the gel strength, storage modulus, salinity tolerance and thermal stability of commonly used polymers have been greatly enhanced. In this paper, the advances in experimental studies on polymer-based nanocomposites are discussed and field experiences from adoption of polymer composites reviewed.
\end{abstract}

Keywords: gel strength; polymer-based nanocomposites; salinity tolerance; thermal stability; water shut-off

\section{Introduction}

Primary and secondary production accounts for recovery of up to $30 \%$ of oil initially in place. To recover the residual oil, tertiary methods are used. When effectively applied, enhanced recovery methods can produce an additional 30-60\% of the oil in the reservoir [1]. Enhanced oil recovery (EOR) processes are broadly classified into thermal or non-thermal methods. Thermal methods apply heat through hot water, steam, or in-situ combustion to reduce oil viscosity for easier mobility [2]. Though they are useful in production of heavy oils their applicability is limited by depth, petrophysical properties of the reservoir and the additional energy costs incurred. Non-thermal methods, on the other hand, improve the sweep efficiency through either miscible or immiscible displacement by gas or chemical injection [3]. Management of water production from mature fields is required in order to accelerate oil recovery. Water cuts have detrimental technical, economic, and environmental effects as they reduce oil production rate, accelerate scaling and corrosion, and result in increased cost of handling and disposal of the produced water [4,5]. Several methods including squeeze cementing and chemical injection using polymers, resins, and surfactants have been applied to manage such conformance issues and prolong the life of the field [6]. Of these chemicals, polymers are the most commonly used and are applied either through polymer flooding or gel treatment [7]. The two differ in their mechanism of enhancing recovery whereby polymer flooding maximizes penetration into low permeability zones that are saturated with oil while gel treatment maximizes entry into well swept high permeability streaks to shut off water [8]. Han et al. [9] classifies the gel treatments into three, based on the conformance problem addressed-i.e., water shut off, profile modification, and in-depth flow diversion. Water shut off treatments are the focus of this review. They are applicable either selectively or non-selectively [10], to manage reservoir heterogeneity by targeting thief zones. Profile modification and in-depth flow 
diversion techniques including colloidal dispersion gels (CDGs) [11], preformed particle gels (PPGs) [12], small microgels [13], and temperature activated polymers (TAPS) [14] have been discussed in other literature.

\subsection{Gel Treatments for Water Shut Off}

Gel treatment using bulk gels is a popular conformance improvement technique used due to its cost effectiveness [15] and proved recovery efficiency [16]. Polymers are easy to inject and have deeper penetration in the reservoir [17] to enhance both vertical and areal sweeping of oil. They increase the viscosity of the water injected and enhance recovery through various mechanisms including reduction of interfacial tension, altering rock wettability, controlling permeability of various zones of the reservoir and reduction of oil viscosity to increase its mobility [18]. Gel treatment involves injection of a polymer solution containing a gelling agent in a target zone to seal it off [19]. The solution typically consists of polymers, crosslinkers, and water at approximately $1.8 \%, 0.2 \%$, and $98 \%$ weight proportions respectively [20]. It is designed such that after a specific time period and at given thermal conditions, a 3D polymer matrix forms by crosslinking of the gelling agents and the polymer macromolecular chains [21].

Base polymers used in the field are either synthetic or biopolymers [16]. Synthetic polymers are mostly derivatives of acrylamides including polyacrylamide (PAM), partially hydrolysed PAM (HPAM), polyvinyl alcohol (PVA), and polyacrylamide/tert-butyl acrylate (PAtBA) (Figure 1). They are common in field applications because they are relatively economical and readily soluble in water, making them convenient to inject [22]. Biopolymers such as xanthan gum and cellulose, on the other hand, are products of fermentation [23]. Although they are environmentally friendly and they formulate high viscosity solutions, biopolymers are quite uncommon in field applications because of the cost implication.

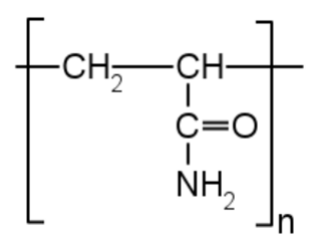

(a) PAM

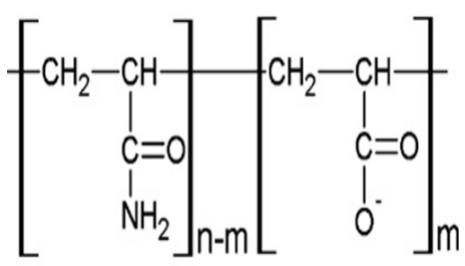

(b) HPAM<smiles>CCC(CC)C(CC)C(=O)OC(C)(C)C</smiles>

(c) PAtBA

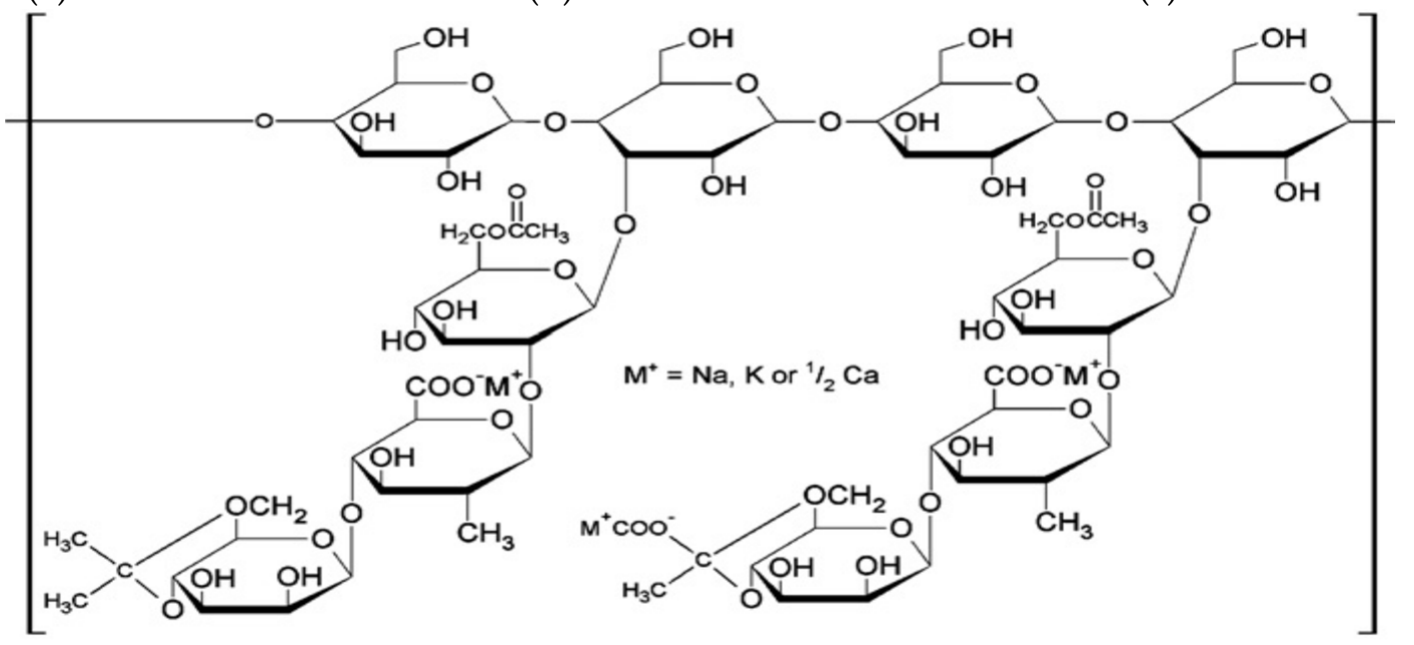

(d) Xanthan Gum

Figure 1. Molecular structures of some common polymers used for water shut off (Adapted from [24,25]). 
The crosslinkers in a polymer solution can either be metallic or organic. Metallic crosslinkers are cations including ions of chromium, zirconium, and aluminium that react by ionic bonding while organic crosslinkers react through covalent bonding [26] Organic crosslinkers such as polyethyleneimine (PEI), phenol, and hexamethylenetetramine (HMTA) form more stable and stronger gels compared to metallic ones. The injected polymer solution transforms into a gel matrix downhole through physical or chemical mechanisms that are dictated by subsurface trigger stimuli such as temperature, formation water salinity or $\mathrm{pH}[27,28]$. The mechanisms are discussed under the polymer sensitivity subsection of this paper. Despite their popularity, optimum performance of polymer gels is inhibited by excessive aggregation that can cause blocking of pores [29]; adsorption of the polymer on the reservoir pore surface [30]; gelation timing [31]; and their instability at high temperature, high pressure and high salinity reservoir conditions [32]. These challenges are briefly discussed below.

\subsubsection{Challenge 1-Aggregation}

It is expected that the viscosity of a polymer solution will increase with increase in polymer concentration because of presence of more polymer chains that self-associate to form larger aggregates. While higher viscosity is required to reduce water mobility and curb issues like fingering; very high polymer concentrations can lead to formation of aggregates that may block the pores and effectively reduce the permeability. The Critical Association Concentration (CAC) of the polymer plays a significant role in the rheology of the polymer hybrid as it is the concentration at which the polymer starts interacting with other substances such as surfactants and nanoparticles [33]. In Haruna et al.'s study [34], at $0.06 \mathrm{wt} . \%$ concentration of HPAM the gradient of the viscosity plot drastically changed with a sharp increase in viscosity observed when the polymer concentration exceeded this threshold value. At concentrations above CAC, there is increased molecular count of polymer in the solution which results in a more pronounced frictional interaction between the polymer chains which can cause instability. Therefore, in nanocomposite analysis, a polymer concentration below CAC is used to avoid the unfavourable polymer intermolecular associations.

\subsubsection{Challenge 2-Polymer Sensitivity}

Polymers respond to downhole stimuli by various physical or chemical mechanisms to form the crosslinked matrix that seals off water producing zones [27]. The four physical mechanisms are: swelling and shrinking; surface charge conversion; assembly and dissociation; and solution to gel transitions. They are temporary and reversible as opposed to chemical mechanisms (like crosslinking and uncapping) that involve permanent bonds. Polymers are overly sensitive to high temperature, high pressure, and high salinity conditions in the reservoir that cause them to degrade and reduce efficiency.

With respect to thermal conditions, the lower critical solution temperature (LCST) and upper critical solution (UCST) temperature of a polymer are critical as they mark the point of transition in phases (i.e., solution to gel) of the polymer [28]. At temperatures between these two, the polymer is readily miscible in the surrounding media at varied compositions [17] while at very high temperatures, the polymer degrades and its chains become mobile [35]. Thermal stability of a polymer nanocomposite is often determined through differential scanning calorimetry (DSC) which measures the quantity of energy required to break the polymer network making the chains mobile and easy to rotate [36]. The temperature at which this degradation happens is called the degradation temperature or glass transition temperature, $T_{g}$. At temperatures above $T_{g}$, the polymer becomes flexible or rubbery. Application of crosslinkers in the hydrogel results in a stronger gel network with increased transition temperature. This reinforced composite matrix ensures appropriate plugging of water producing zones at elevated temperatures downhole.

PAM has been reported to flocculate at high salinity and degrade at high temperatures because the acrylamide functional group transforms to carboxylic or acrylate com- 
pounds [37]. The presence of divalent ions such as $\mathrm{Ca}^{2+}$ in the formation water further speeds up PAM precipitation [38]. Hydrolysing PAM helps to reduce its sensitivity to salinity. It, however, still remains thermally and mechanically unstable as the amide groups of HPAM are prone to hydrolysis into carboxylic acid at high temperatures and precipitation in presence of divalent cations. Moreover, at high pump pressures, polymer chains undergo shearing that reduces the apparent viscosity [23]. Zhu et al. [39] reported that by copolymerizing acrylamide with $\mathrm{N}$-(4-bezoyloxy)-acrylamide and dimethylamino ethyl methacrylate (DMAEMA) to form hydrophobically associating partially hydrolysed polyacrylamide (HAHPAM), the shearing tendency of HPAM could be controlled. This was the case because $\mathrm{N}$-(4-bezoyloxy)-acrylamide formed the stable parent chain of HAHPAM copolymer in place of the unstable acrylamide group that was the backbone of HPAM. Organic crosslinkers, such as polyethyleneimine (PEI), have also been applied to manage thermal stability [40].

Poly(vinylidene fluoride) (PVDF)-based hydrogels have also demonstrated improved thermal stability and chemical resistance. Recent developments in this technology have unveiled the potential of these hydrogels in controlling water flow by fabricating a porous membrane structure in the polymer composite. Yuan et al. [41] synthesized a cross-linked composite hydrogel using pentaerythritol tetrakis (3-mercaptopropionate) (PETMP) and PVDF. This composite was reported to have a better water trapping ability because of increased surface roughness as observed in the SEM images. Zhao et al. [42] recorded a one-step strategy to fabricate pores on PVDF-based polymer composites through superspreading, phase inversion, and membrane formation. This process yielded an asymmetric membrane structure in which one side possessed hydrophilic micropores while the other side had hydrophilic nanopores. This asymmetry was proved to be beneficial in controlling the osmotic pressure and hence water flow characteristics through the PVDF composite. Later, Abolhasani et al. [43] proposed a new technique of inducing nanopores in PVDF-based hydrogels called liquid-phase demixing that utilizes the thermodynamic properties of hydrogel solutions. Their study fabricated poly (vinylidene fluoride-co-trifluoro ethylene) - PAN composite that was effective in preventing water ingress because of the strong repulsion with water.

\subsubsection{Challenge 3-Proper Polymer Placement}

For effective performance, the polymer gel must be placed properly at target zones. During injection, it is desired that the polymer should retain its rheological properties and only crosslink into a gel after it reaches the intended zone. If the polymer gels prematurely, which is likely at high downhole temperatures, it will be inappropriately placed increasing cost of pumping through the wellbore tubulars [31]. Various parameters such as gelation time are used to characterize the gelation kinetics of hydrogels. Gelation time is the period taken by the polymer solution to transform to gel at a specific temperature [44]. The energy stored in the gel is called storage modulus $\left(G^{\prime}\right)$ which indicates the elasticity of the semi-solid gel. Loss modulus $\left(G^{\prime \prime}\right)$, on the other hand, is a measure of the amount of energy given out as heat [36]. The ratio of the storage modulus to the loss modulus $\left(G^{\prime} / G^{\prime \prime}\right)$ then characterizes the gel strength of a polymer gel. The behaviour and performance of the formulated polymer gel is described by the resistance factor (RF) given by the ratio of water mobility to the mobility of the polymer as given by Equation (1) [45,46]. After gel treatment, the fluid mobilities are characterized by the residual resistance factor (RRF) given by Equations (2) and (3).

$$
\begin{aligned}
\lambda & =\left(\frac{k_{\text {fluid } 1}}{\mu_{\text {fluid } 1}}\right) \\
R F & =\left(\frac{\lambda_{\text {water }}}{\lambda_{\text {polymer }}}\right)
\end{aligned}
$$




$$
R R F_{\text {water/oil }}=\frac{\lambda_{(\text {water/oil }) \text { before }}}{\lambda_{((\text {water/oil }) \text { after }}}
$$

Considerably significant control of gelation time has been established by crosslinking the polymer chains with a nanofiller which reduces its sensitivity to electrolytes and temperature [40]. Organic crosslinkers such as PEI and phenol have been applied as retarders to delay gelation for effective placement especially in deep reservoirs [47]. In one study [25], the advantageous gelation kinetics and success reports from field cases of PEI crosslinked polymer systems are discussed extensively. The study revealed the need for incorporation of additives to the polymer systems to prevent PEI from attacking the base polymers. Nanoparticles were recommended over inert solids and retarders for this purpose.

In a different study by El Karsani et al. [40], applying PEI as a crosslinker for PAM gel showed a longer gelation delay but lower gel strength in presence of $\mathrm{NH}_{4} \mathrm{Cl}$ compared to $\mathrm{NaCl}$ electrolytes. It is believed that the $\mathrm{NH}_{4}{ }^{+}$ions have a greater shielding effect than $\mathrm{Na}^{+}$ thus reducing the crosslinking between PEI and PAM. It is important therefore, that whilst seeking better control of gelation, the compositions of the composite and formation water be considered so as not to affect quality of shut off achieved. Other factors governing gelation and stability of organically cross-linked polymer gels including reactant concentrations and $\mathrm{pH}$ have been reviewed elsewhere [48].

Interest has grown, in the recent past, on the application of nanoparticles (NPs) in polymer hydrogels for high temperature and high salinity applications. Because of their small particle size, NPs have a higher concentration of atoms on their surface causing them to exhibit unique physical and chemical properties compared to the material's properties in bulk form [18]. Researchers have found these properties useful for a wide range of applications. In the oil and gas industry, nanoparticles have been applied in drilling fluids, cementation, stimulation operations and enhanced oil recovery [49]. Their application in nano-sensors, nano-membranes, nano-catalysts, and nanofluids in the petroleum industry has been presented comprehensively in literature [50]. In the following section, we review experimental studies that have been carried out using nanoparticles for the purpose of enhancing the properties hydrogels. The mechanisms behind the improvements recorded are discussed from a chemistry perspective. Thereafter, field experiences from application of polymer composites are presented. The three classes of nanoparticles used for the purpose of water shut off for EOR discussed below are: metal and metal oxide-based nanoparticles, inorganic nanoparticles (silica), and organic nanoparticles (graphene and carbon nanotubes) [18].

\section{Experimental Studies on Polymer Nanocomposites}

\subsection{Metal and Metal Oxide-Based Nanoparticles}

The use of metal-based nanoparticles for EOR has been extensively studied but their incorporation in polymer gels is still relatively unexplored. Several studies have reported enhanced oil recovery by using oxides of aluminium, titanium, zinc, and magnesium at nanoscale [51,52]. They are particularly effective for production of heavy oil by reducing its viscosity, reducing interfacial tension (IFT) and changing the reservoir wettability to water wet due to their hydrophilic nature [53]. Even though their adsorption tendency is a mechanism for enhancing oil recovery, most of the nanofluid injected could be wasted if adsorbed onto untargeted zones of the formation. By incorporating these nanoparticles in polymer gels, such a challenge can be addressed. Metal-based NPs act as a crosslinker for polymer gels to create stable matrices [54]. $\mathrm{Xu}$ et al. [55] used $\mathrm{TiO}_{2} \mathrm{NPs}_{\text {in co-polymerized }}$ acrylic acid (PAA) \& N,N-dimethylacrylamide (DMAA) hydrogel to improve the tensile and compressive strength of the polymer. They recorded significant improvement which was attributed to the ester and hydrogen bonds between $\mathrm{TiO}_{2} \mathrm{NPs}$ and the free carboxyl groups of PAA chains. This improved toughness was believed to activate a shape memory effect where the polymer nanocomposite recalled and regained their previous shapes when responding to various stimuli. It is desired that an appropriate balance between strength (as 
characterized by elastic moduli such as Young's Modulus) and toughness of the resulting nanocomposite gel be maintained [56]. This will ensure that the gel formed downhole will appropriately absorb impact energy without fracturing, hence guaranteeing the integrity of water shut off attained, particularly for long term.

Similar improvements were reported by Huerta-Angeles et al. [57] who applied titanium dioxide $\left(\mathrm{TiO}_{2}\right) \mathrm{NPs}$ in Poly(N-isopropylacrylamide) (PNIPAM) hydrogel through freezing polymerization to control salinity and temperature sensitivity of the polymer. $\mathrm{TiO}_{2}$ NPs were observed to mechanically strengthen the polymer and increase the swelling by stabilizing the composite's pore structure. In another study [22], the effect of $\mathrm{TiO}_{2} \mathrm{NPs}$ on HPAM for the production of heavy oil $(1320 \mathrm{cP})$ is presented. Through core flooding experiments in sandstone formation, it was shown that $\mathrm{TiO}_{2} \mathrm{NPs}$ improves the viscosity of HPAM gel thus enhancing sweeping of the oil. A $4 \%$ increase in oil recovery was recorded at a threshold NP concentration of $2.3 \mathrm{wt} \%$.

Zirconium hydroxide $\left(\mathrm{Zr}(\mathrm{OH})_{4}\right)$ is also a good candidate for crosslinking polymer nanocomposites because it has several hydroxyl groups useful for hydrogen bonding [58]. Jiang et al. [59] used $\left(\mathrm{Zr}(\mathrm{OH})_{4}\right)$ NPs to crosslink copolymerized acrylamide (PAM) and 2-acrylamido-2-methyl propane sulfonic acid (AMPS) in the presence of $\mathrm{N}, \mathrm{N}, \mathrm{N}^{\prime}, \mathrm{N}^{\prime}$-Tetramethylethylenediamine (TEMED). They observed a strong hydrogenbonding network between the amide group of PAM and sulfonic acid group of AMPS which exhibited a high mechanical strength and increased self-healing efficiency. In a later study [36], $\left(\mathrm{Zr}(\mathrm{OH})_{4}\right) \mathrm{NPs}$ were used to enhance thermal and viscoelastic properties of PAM organically crosslinked with hydroquinone $(\mathrm{HQ})$ and HMTA. Incorporation of $0.2-0.8 \mathrm{wt} \%$ of the $\left(\mathrm{Zr}(\mathrm{OH})_{4}\right) \mathrm{NPs}$ was seen to increase thermal stability by 3 to $5{ }^{\circ} \mathrm{C}$. The hydroxyl groups of the organic crosslinkers are believed to have improved PAM- $(\mathrm{Zr}$ $\left.(\mathrm{OH})_{4}\right)$ interactions by attaching to amide $\left(-\mathrm{CONH}_{2}\right)$ group of PAM by covalent bonds (via $-\mathrm{CH}_{2} \mathrm{OH}$ ) and hydrogen bonds (via $-\mathrm{OH}$ ). These interactions resulted in a strongly linked polymer gel with limited chain mobility that required higher endothermic energy to break hence the improved stability observed. Moreover, being hydrophilic in nature, PAM- $\left(\mathrm{Zr}(\mathrm{OH})_{4}\right)$ nanocomposite formed hydrogen bonds with water (making it bound water) improving the gel's water retention capacity.

Consistent with Jiang et al.'s study, the hydrogen bonds formed between the polymer nanocomposite and bound water were reversible allowing a self-healing phenomenon for $\left(\mathrm{Zr}(\mathrm{OH})_{4}\right)$-polymer nanocomposites. This behaviour improved the elasticity of the polymer nanocomposite.The idea of self-healing hydrogels has gained importance recently as a solution for extending the life of hydrogels and reducing cost. Self-healing gels automatically repair themselves through spontaneous response to various stimuli including light, heat, force, $\mathrm{pH}$, or salinity $[60,61]$.

Almohsin et al. [62] investigated this self-healing property of $\mathrm{PAM}-\mathrm{Zr}(\mathrm{OH}) 4$ nanocomposite prepared in presence of ammonium persulfate (APS) and tetramethylethylenediamine (TEMED). They observed improved storage modulus (from 2000 to $2060 \mathrm{~Pa}$ ) and loss modulus (from 627 to $644 \mathrm{~Pa}$ ) compared to neat PAM hydrogel. Keishnan et al. [63] also reported enhanced thermal and rheological properties of PAM crosslinked with $\mathrm{N}, \mathrm{N}^{\prime}$ methylenebis acrylamide (MBA) in presence of $\mathrm{Zr}(\mathrm{OH})_{4}$ and $\left(\mathrm{Zr}(\mathrm{OH})_{4}\right) \mathrm{G}$ nanoparticles. The organic crosslinker was observed to decrease the PAM chain mobility thus decelerating its degradation. At $0.15 \mathrm{wt} \%$ concentration of MBA the glass transition temperature recorded was $175{ }^{\circ} \mathrm{C}$ which increased to $181{ }^{\circ} \mathrm{C}$ at $0.3 \mathrm{wt} \%$ MBA concentration. Even higher degradation temperatures were recorded for the nanocomposite hydrogels proving that the NPs form weak crosslinking bonds with PAM reducing its degradation enthalpy. In addition, the nanocomposites were observed to have higher elasticity than neat PAM hydrogel. PAM/MBA/ $\left(\mathrm{Zr}(\mathrm{OH})_{4}\right) \mathrm{G}$ exhibited the highest storage modulus of $1920 \mathrm{~Pa}$ compared with PAM/MBA/ $\left.\mathrm{Zr}(\mathrm{OH})_{4}\right)$ and PAM/MBA that recorded $1900 \mathrm{~Pa}$ and $1000 \mathrm{~Pa}$ respectively. The study demonstrated that zirconium nanocomposite hydrogels exhibit a higher degree of energy dissipation while the hydrogels stored most of the shear energy applied to them. 
Iron oxide being magnetic offers better control for placement of polymer hydrogels through the application of an external magnetic field. Besides, by utilizing this magnetic property the efficiency of removal of polymers from the produced water can be tremendously increased to meet environmental discharge regulations. In Ko et al.'s study [64] functionalized magnetic particles were applied to recover HPAM from return water. An efficiency of $90 \%$ was recorded, which was attributed to the electrostatic interaction between the NPs and the polymer.

Aluminium NPs were applied by Suleimanov et al. [65] in a biopolymer-based gel formed by crosslinking carboxymethylcellulose $(\mathrm{CMC})$ with a metal salt. The nanogel was tested by core flooding under Shallow Water Guneshli (SWG) oilfield conditions $\left(62{ }^{\circ} \mathrm{C}\right.$, $16 \mathrm{MPa}$, sandstone-claystone formation with $195 \mathrm{mD}$ permeability). The comparative performance of the polymer gel against the nanogel was characterized by the residual resistance factor. A $22 \%$ increase in (RRF) of the nanogel was recorded and $4.5 \%$ improvement in oil recovery reported for the lower permeability zone. It is believed that the application of the NPs in the gel formulation enabled in-depth fluid diversion hence the increased production from the tight zones.

\subsection{Inorganic Nanoparticles-Silica}

Silica is a low-cost NP that is readily available and can be synthesized easily at large scale. It is highly hydrophilic due to the presence of silyl alcohol $\left(\mathrm{SiH}_{3} \mathrm{OH}\right)$ groups that are polar [32]. When used in polymer gels, it causes alteration of the wettability of the rock to enhance oil recovery. An early experimental study with silica was reported by Whitby et al. [66] who observed increased viscosity and a stable structure when silica nanoparticles were used in polyacrylic acid and polyethylene polymer gels. Later, Maghzi et al. [32] reported improved salinity tolerance of PAM specifically in presence of divalent cations when silica NPs were applied. By monitoring the sweep patterns of various compositions of polymer nanocomposites in a micromodel and the fluid viscosity, they observed that as salinity increased, the viscosity decreased to a given minimum as did the oil recovery. The ion-dipole interaction (illustrated in Figure 2) between the salt cations and the PAM functional groups i.e., amino group $(\mathrm{N}-\mathrm{H})$ \& oxygen $(\mathrm{C}=\mathrm{O})$ resulted in weakening of the bonds. This degradation effect was more pronounced in the presence of divalent cations $\left(\mathrm{Ca}^{2+}\right.$ and $\left.\mathrm{Mg}^{2+}\right)$ due to their higher charge densities. Beyond the minimum viscosity point, a reverse phenomenon was observed where an increase in salinity resulted in a slight increase in viscosity. In overall, a $10 \%$ increase in recovery was observed with the nanocomposite. The addition of silica enhanced the viscosity of the polymer by forming covalent bonds with the oxygen atoms in PAM. Moreover, due to its hydrophilic nature, silica is easy to wet and it readily prevents the attack on oxygen atoms of PAM by the salt cations. In this way, silica NPs in PAM introduces competition for the salt cations thus preventing polymer degradation in high salinity conditions. These results were later affirmed by Maurya et al. [67] who observed increased viscosity and salt tolerance in silica-PAM hybrids. In another study, Zhu et al. [39] observed that hydrophobically associating partially hydrolysed polyacrylamide (HAHPAM)-silica hybrid resulted in improved shear stability at high temperature $\left(85^{\circ} \mathrm{C}\right)$ and high salinity $(32,868 \mathrm{mg} / \mathrm{L}$ TDS in presence of $\mathrm{Ca}^{2+}$ and $\mathrm{Mg}^{2+}$ ). This performance was attributed to the hydrogen bonds formed between the amide functional group of HAHPAM and silanol of silica. With silica NPs present, HAHPAM undergoes microstructural strengthening by interactions between the amide group of HAHPAM and silanol of silica that increase the storage modulus of HAHPAM-silica hybrid. A higher elastic modulus means higher oil mobility and hence higher oil recovery factor at high temperature and high salinity conditions. The impact was more pronounced at higher silica concentration because then, the mobility of polymer chains was limited. 


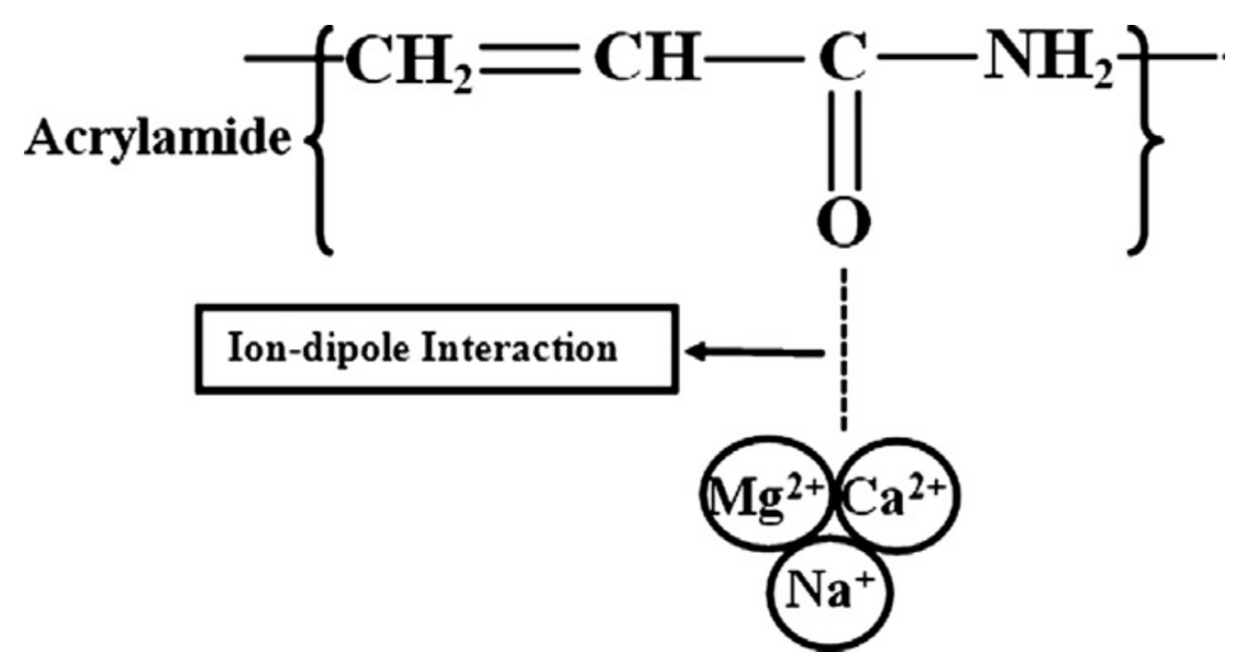

(a)

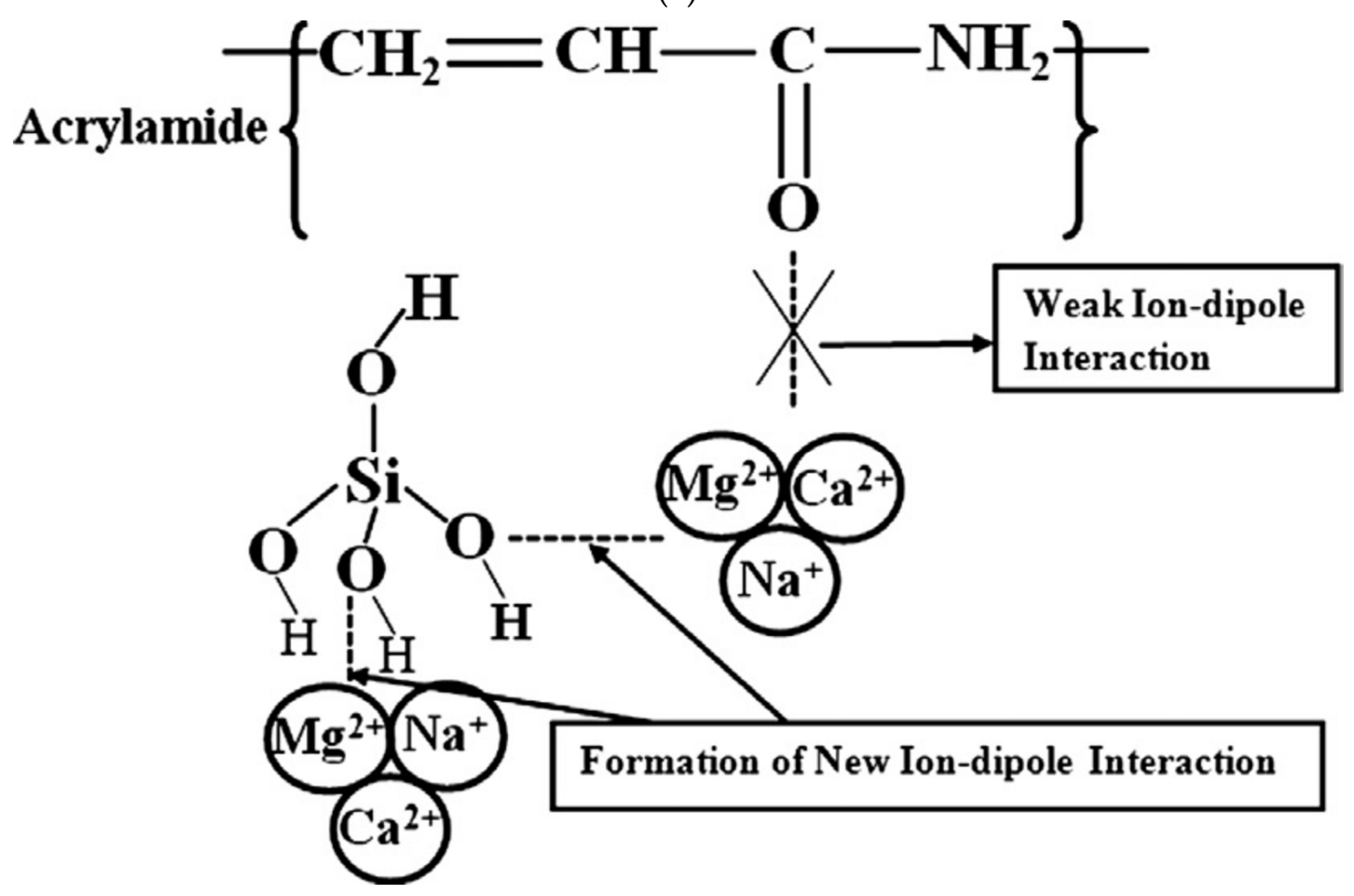

(b)

Figure 2. (a) Proposed interaction between magnesium, sodium and calcium cations with the carbonyl group of PAM solution without silica nanoparticles; (b) Weakened ion-dipole interaction with carbonyl group of PAM with the presence of silica nanoparticles due to the formation of new bonds with the nanoparticles [32].

The enhancing effect of silica NPs can also be explained through adsorption-desorption mechanism [23]. The experimental adsorption data, in this study, fitted the solid-liquid equilibrium (SLE) model [68] yielding a Type III adsorption isotherm. They postulated that by adsorption of the polymer on the surface of silica, the reactivity of HPAM functional groups was inhibited thus polymer degradation in oxidizing conditions was prevented. Adsorption of the polar constituents of HPAM on the functional silanol groups of silica NPs was favoured at high concentrations of HPAM. As reported by Zhao et al. [69] the nanoparticles added acted as nucleation sites for growing the polymer network. At higher temperatures there was increased hydrolysis. In the presence of silica NPs, a stable silica- 
HPAM network was formed through crosslinking that decelerated viscosity reduction with temperature increase and inhibited polymer aggregation.

It is also desired that a polymer composite retains its properties over a long period of time under the harsh reservoir conditions for it to be useful in enhancing oil recovery for long term. Thermal stability with aging is therefore sought when formulating the polymer gels. In laboratory analysis, the ability of the polymer gel to retain its apparent viscosity at high temperatures over prolonged time periods is used to deduce the aging property. In Zhu et al.'s study [39], silica NPs were shown to improve long term thermal stability of HAHPAM as the HAHPAM-silica hybrid was observed to retain $33.83 \%$ of the design viscosity while pure HAHPAM retained less than $5 \%$. This was attributed to the ability of silica to prevent hydrolysis of the amide groups in HAHPAM thus inhibiting degradation. Despite silica's potential in improving thermal and salinity tolerance of commonly used polymers, its incompatibility with some polymers and requirement for modifications hinders its wide application in the field. Zheng et al. [70] sought to improve silica's performance through in-situ surface modification using silane coupling agents-i.e., hexamethyldisilane (HM) and hexadecyltrimethoxysilane (HD)—for its application in enhancing HPAM for high temperature and high salinity reservoirs. Through this modification, the hydrophobic groups of silica would act as crosslinkers by physically interacting with HPAM to reduce its sensitivity. They observed that, through this physical hydrophobic crosslinking in combination with the hydrogen bonds formed, a stable 3-D polymeric structure was formed that exhibited higher viscosity even at elevated temperatures $\left(90^{\circ} \mathrm{C}\right.$ ) and simulated saline conditions (TDS: $5727 \mathrm{mg} / \mathrm{L}$ ). Dai et al. [71] developed a new technique of applying silica NPs called the core-shell technology that enhances the stability of the gel. They synthesized silica NP core with polymer shell that proved efficient in reducing IFT and improving the viscosity of the injected water.

According to Liu et al. [72], silica NPs have a strengthening effect on PAM polymer crosslinked with HQ and HMTA. These crosslinkers have also been reported to enhance gelation and thermal performance of PAM in other studies [73]. The presence of silica NPs was observed to reduce gelation time and increase the gel strength and storage modulus of the nanocomposite. This behaviour was attributed to doping of the hydrogel in presence of silica NPs. As the concentration of silica was increased, the NPs aggregated and attached along the polymer chains to form microscopic 3D network structures with improved strength and elasticity and reduced the gelation time. In addition, DSC studies revealed that samples with silica NPS remained stable up to $155{ }^{\circ} \mathrm{C}$ as contrasted with a maximum of $137.8^{\circ} \mathrm{C}$ attained by neat PAM gels demonstrating an improvement in the thermal stability. Silica NPs are negatively charged and they contain many hydroxyl groups that bond with water molecules in the solution through hydrogen bonding. The synergy of this hydrogen bonds and electrostatic attractions between the hydronium ions enhances the hydrophilicity of the nanocomposite causing it to retain more water and remain stable at elevated temperatures.

Chen et al. [74] investigated the performance of PAM/PEI hydrogel in the presence of nano-silica for water shut off. They recorded significant inhibition of syneresis of the hydrogel and improved gel strength. The strength was drawn from the strong mesh structure formed by crosslinking of silanol groups of silica with amide groups of PAM through hydrogen bonding. This reinforcement was responsible for improved stability from 18 days to 180 days at $130^{\circ} \mathrm{C}$. The sand pack flow test revealed a high water shut off ratio and residual resistance factor for the nanocomposite.

Asadizadeh et al. [75] also reported consistent results when they investigated the effect of $\mathrm{SiO}_{2}$ on the strength and thermal stability of HPAM crosslinked with chromium (III) acetate. It was noted that the elastic modulus of the polymer nanocomposite increased by $8.4 \%$ in sea water and by $18 \%$ in formation water. This improvement in gel strength was due to the additional cross-linking joints offered by silica NPs. The nanogel demonstrated tremendous flexibility even at elevated temperatures $\left(100^{\circ} \mathrm{C}\right)$ as it could be elongated by $1150 \%$. Moreover, the presence of silica nanoparticles significantly enhanced thermal 
stability as indicated by the inflexion temperatures of the samples. The sample with 10,000 ppm HPAM, $0.1 \mathrm{wt} . \%$ chromium (III) acetate and $2000 \mathrm{ppm}$ silica recorded $157.9^{\circ} \mathrm{C}$ inflexion temperature compared with $140.8^{\circ} \mathrm{C}$ for the same sample without silica. At temperatures above the inflexion point, the samples would have lost all the water by evaporation leading to decomposition of the gel structure. Silica also effectively reduced the swelling ratio of the nanogel by reducing the hydrophilic groups present in the nanogel, consequently lowering the osmotic pressure. The study conclusively demonstrated the potential of silica in improving mechanical strength, thermal stability, and salinity tolerance of HPAM.

Besides $\mathrm{SiO}_{2}$, interest has also developed in the use of nano-clays which are silica derivatives made of layered structures [76]. Their structure offers a large surface area useful in formation of polymer nanocomposites. Cheraghian et al. [77] observed that addition of nano-clay in PAM hydrogel resulted in 5.8\% increase in oil recovery at high temperature $\left(80^{\circ} \mathrm{C}\right)$ and high salinity. Recovery was seen to decrease as the salinity of the electrolyte was increased up to a maximum test value of 20,000 ppm.

Elsewhere, Saghafi et al. [78] applied nano-clay in pre-formed particle gels (PPGs) formulated using different polymer species (AMPS-Sodium salt, acrylamide, $\mathrm{N}$-vinylpyrrolidone (NVP), and N, N-dimethylacrylamide (DA)) to control stability at high temperature $\left(145^{\circ} \mathrm{C}\right)$ and high salinity $(225,000 \mathrm{mg} / \mathrm{L})$ reservoir conditions. The study established that at $2.5 \mathrm{wt} \%$ of nano-clay, the polymer nanocomposite exhibited highest thermal stability and reduced swelling ratio. This behaviour was attributed to the intercalated structure formed by the polymer-clay composite. The polymer is believed to attach to the flat surface of clay which possesses a negative charge. With a decreased swelling ratio, the crosslinking density increases consequently improving thermal stability. An improvement in thermal stability was also observed by Pu et al. [79] who studied the performance of PAM/PEI-MMT polymer nanocomposite at high-temperatures $\left(120^{\circ} \mathrm{C}\right)$. The presence of the silicate Montmorillonite (MMT) nanoparticles was reported to increase the gel strength and thermal stability of the nanocomposite for longer periods (90 days in this case). The composite was, however, observed to be sensitive to high salinity that caused delay in gelation time.

Singh et al. [80] synthesized nano fly ash- PAM polymer composite crosslinked with chromium acetate. The synthesized gel was shown to have increased strength and plugging ability. It was believed that nano fly ash offered new sites for crosslinking with the polymer or increased mobility of polymer molecules at elevated temperatures $\left(90^{\circ} \mathrm{C}\right)$ to reduce the gelation time (9-10 h). In addition, the low activation energy of this nanocomposite enhanced rapid gel formation. This study presented a relatively cheap alternative for enhancing properties of conventional bulk gels applicable to fractured and highly heterogenous reservoirs requiring intense gel applications. Success reports on the effectiveness of silica NPs in biopolymers have also been documented. Kennedy et al. [81] applied silica NPs in xanthan gum crosslinked with locust bean gum and observed an increase its viscosity.

\subsection{Organic Nanoparticles}

Graphene is a carbon derivative often applied at nanoscale. It has excellent mechanical, thermal, and electrical properties that makes it applicable in many areas including solar cells [82], chemical sensors [83], and polymer nanocomposites. It is highly preferred for polymer nanocomposites because it has a 2D geometry composed of planar sheets formed by $\mathrm{sp}^{2}$ hybridized carbon atoms that have very high elastic moduli and thermal conductivity [84]. Enhanced mechanical strength is significant for the polymer composites to withstand downhole overburden pressures and resist pressure variations due to drawdown. To attain the amplified properties of graphene, single layers of graphene sheets are exfoliated from graphene oxide. Given their hydrophilic nature, due to the presence of oxygenated functional groups, graphene nanosheets can be uniformly dispersed in water [21]. They also offer great gelation control due to their amphiphilic tendency-i.e., they contain hydrophilic edges and hydrophobic sheets that can form super-architectures and 
slow down precipitation [85]. Some reported experimental observations using graphene in polymer hydrogels are discussed below.

Graphene nanosheets, at low concentration, were observed to increase the tensile strength of polyvinyl alcohol polymer in one study [69]. At low concentration, there was uniform dispersion of the graphene nanosheets in the polymer matrix thus enhancing the composite crystallinity. Increasing graphene concentration beyond $1.8 \mathrm{vol} \%$ resulted in no significant improvement. To explain this observation, three mechanisms that enhanced the composite crystallinity below the critical concentration were postulated: uniform dispersion, weak edge-edge links of graphene nanosheets and slight overlapping. It is believed that beyond the critical concentration value, stronger Van der Waals attraction caused restacking of the nanosheets, a phenomenon they termed as mechanical percolation. This concept of a threshold concentration was also observed by Alzari et al. [86]. In their study, a drastic increase in viscosity and storage modulus $G^{\prime}$ were recorded when graphene nanosheets were added to poly(N-isopropylacrylamide) (PNIPAM) hydrogel. It was noted that $\mathrm{G}^{\prime}$ increased with graphene concentration to a maximum value beyond which it falls even below that of pure PNIPAM. This observation was explained by the change in the composite's non-Newtonian behavior from thermoset (below critical concentration) to thermoplastic (above the critical concentration) with addition of graphene. It was noted that at high concentration of graphene nanosheets (above $0.13 \mathrm{wt} \%$ ), graphene exhibited a lubricating behaviour that adversely affected both $G^{\prime}$ and viscosity.

Another study [21] evaluated the effect of graphene oxide (GO) NPs on the strength of PAM hydrogels synthesized by frontal polymerization. They observed a denser structure, higher modulus, and increased thermal stability of the polymer nanocomposite (GO-PAM) compared to PAM hydrogel which was attributed to the increased cross-link density. The crosslinking reaction reduced the swelling ratio of GO-PAM composite because the GO nanosheets acted as junctions for crosslinking with PAM. This study also revealed that the concentration of GO in the composite, characterized by $m / n$ ratio (where $m$ is the GO concentration and $n$ is polymer concentration) influenced the resulting tensile properties. At high $m / n$ ratio (high GO concentration), the stress applied on the nanocomposite was evenly distributed in the polymer microstructure making the composite tough while at low $\mathrm{m} / \mathrm{n}$ ratio there was random crosslinking and uneven stress distribution resulting in a feeble structure. This effect of enhanced mechanical strength and elasticity was easily demonstrated by an elongation test in which the polymer nanocomposite was shown to be very flexible to the point of tying a knot.

A similar observation was made by Liu et al. [87] who synthesized GO-PAM nanocomposites through free radical polymerization. The resulting composite was observed to have 4.5 times more tensile strength and more than $300 \%$ elongation. In addition, more hydrogen bonds were formed between the hydrophilic PAM chains $\left(-\mathrm{CONH}_{2}\right)$ and water, and between $\mathrm{GO}(-\mathrm{COOH})$ and water further strengthening the composite. The swelling tendency was also seen to reduce because of the physical interactions between GO and PAM polymer chains reducing water absorption. In both studies [21,87], the swelling ratio increased with temperature due to weakening of the hydrogen bonds. A recent development in the application of polymer gels is the polymer microspheres (PMs) which can be used at a nano-scale [88]. Because of their spherical geometry and low calibration diameter they have higher penetration making them effective for low and ultra-low permeability reservoirs that are not suited for high MW polymers. A field case study featuring this technology is discussed later in this article. Almoshin et al. [89] developed a graphene-based zirconium oxide nanocomposite with PAM. The nanocomposite exhibited outstanding mechanical strength at high temperatures. The crosslinking synergy of the graphene and zirconium oxide formed a homogeneous and very stable 3D network. SEM revealed a smooth microstructure with the ability to lock water even at high temperatures and improve the gel strength. This was attributed to the interfacial interaction between the polymer and the NPs; and the high surface area offered by GO nanosheets. This synthesized nanocomposite recorded higher degradation temperatures depending on the 
NP concentration up-to $685^{\circ} \mathrm{C}$. It is environmentally friendly suitable for application in deep reservoirs with minimal modifications to current practices.

Functionalized multiwall carbon nanotubes (MWCNTs) have also been reported to significantly improve the mechanical strength and water adsorbing capacity of hydrogels. In their study, Shakeri et al. [90] synthesized a composite polymer hydrogel by incorporating functionalized MWCNTs in polyacrylic acid-co-maleic anhydride hydrogel. The resulting composite recorded increased tensile strength up-to to twice as much as that recorded for pure hydrogel. This strengthening was attributed to the reduction in interlayer spacing of the polymer matrix with the addition of the functionalized MWCNTs. Furthermore, it was observed that the hydrophilic hydroxyl and carboxyl functional groups in MWCNTs enhanced the water adsorption tendency in the polymer matrix thus improving the swelling capacity of the composite hydrogel. Fine functionalized MWCNTs uniformly dispersed in the composite were reported to be more advantageous with their performance reported to improve with increase in concentration.

Attaining and maintaining a homogeneous dispersion in polymer composites reinforced with CNTs remains to be a challenge. Various studies have attempted to enhance the bond between CNTs and the polymer matrix through heat treatment and applying various controlled crystallization techniques. One novel approach to address this challenge was proposed by Shirvanimoghaddam et al. [91] who applied the concept of selective localization to place the polymer on the surface of the CNTs to obtain a 'cheetah skin' structure with enhanced performance. The composite developed in their study was composed of short MWCNTs coated with uniformly dispersed polyacrylonitrile (PAN) in poly(methyl methacrylate)(PMMA) matrix. This resulting structure exhibited homogeneous dispersion, improved chemical reactivity and thermal stability. The structure is believed to have an influence on adhesion forces that prevents the slipping of CNTs in the composite network.

The potential of metal-organic frameworks (MOF) in providing structural flexibility and stability of composite hydrogels has gained increased research interest in the recent past. By leveraging on the synergy of organic additives such as graphene and metal nanoparticles, reinforced porous structures can be fabricated that exhibit unique properties for versatile applications. Wang et al. [92] presented a detailed review of these MOFs highlighting various synthesis methods and their advantageous properties including increased surface area, porous structure, improved electrical conductivity, and recyclable nature.

\section{Field Experiences of Hydrogels and Polymer Nanocomposites}

As earlier mentioned, mechanically sealing perforations near the OWC and squeeze cementing were traditionally used to manage conformance issues in mature assets but limited success has been reported for the techniques. The use of polymer gels has instead been successfully implemented with significant control achieved. In this section, we review some success records of polymer application in field scale and emerging trends in adoption of polymer nanocomposites. A summary of the field properties for the cases reviewed is given in Table 1.

\subsection{Fields in the North Sea, UK}

i Heather Field, North Sea

Heather field is an oilfield located in the North sea whose initial reserves were estimated to be 422 million stock tank barrels (MMSTB) accumulated in the two-layered Brent sandstone reservoir [93]. After about 15 years of production, just $26 \%$ of the oil had been recovered from the field and at this point it was heavily water-cut. A production $\log$ from well H-43 established that all the water produced was from the upper layer of the reservoir. Initial attempts to shut off these water producing zones through squeeze cementing proved ineffective as the cement would break off within months necessitating remedial cementing. Application of polymer gel was opted for, owing to its ease of injection and deep penetration into the formation. To allow for delay in gelation and enhance its effectiveness at high temperatures $\left(350{ }^{\circ} \mathrm{F}\right)$ and high-pressure gradients downhole, an 
organic crosslinker was incorporated into the gel. A laboratory test established that the organically crosslinked hydrogel could withstand pressure gradients of up-to $1000 \mathrm{psi} / \mathrm{ft}$ as contrasted to chromium acetate-polymer gels that could stand a maximum of $400 \mathrm{psi} / \mathrm{ft}$. Moreover, pump failure during gel injection did not result in premature gelation further confirming gelation control offered by the organic crosslinker. The oil production after the polymer treatment increased by 300 barrels per day (BOPD) while water production reduced by 2290 barrels per day (B/D). This technique offered a long-term solution to the conformance problem as a production log done after 8 months showed complete shut off of the water producing zones of upper Brent formation.

ii Statfjord Field

Statfjord is an offshore oilfield located between Norway and British waters also producing from Brent sandstone layers [94]. Due to $100 \%$ water cuts from the lower Brent interval, oil production started declining in 1993 necessitating a water shut off procedure. 1500 barrels of polymer silicate gel was successfully pumped into this lower interval through a coiled tubing. The gel treatment was described as an economic success because it resulted in an increase in oil production grossly valued at 15 million US \$ over a six-month period paying back for the operation cost in less than two months. Water production was reduced from $84 \%$ to $68 \%$.

iii Miller Field, UK

Miller field is an offshore oilfield producing from layered shale and sandstone formations [95]. With the field experiencing $75-100 \%$ water cuts and failed attempts to mechanically seal of the perforations, chemical treatment was devised for selective shutting off of water to allow only oil production. The chemical formulated consisted of PAM-AMPS copolymer crosslinked with zirconium [96]. Given the high temperature conditions of its reservoir $\left(121^{\circ} \mathrm{C}\right)$, AMPS offered thermal stability by preventing degradation of the amide backbone of PAM. Medium molecular weight (MW) of the polymer was selected because a low MW polymer would result in a rigid structure that would hinder oil production while a high MW polymer would be flexible but difficult to handle. Sodium acetate was added as a $\mathrm{pH}$ buffer to prevent hydrolysis of the zirconium crosslinker. A series of three gel treatments were done in the Miller field resulting in an average water cut reduction of $60 \%$ and up-to $150 \%$ increase in oil production. The same polymer composite was applied in two other fields, Well A02 in the Gulf of Mexico and Well A08NS in the North Sea where a stable polymer block was deployed that remained intact over months.

\subsection{Southeast Kuwait Field}

This field has been producing since 1989 from a sandstone reservoir [97]. A well production test in the mature phase of the field indicated that $90 \%$ of the $300 \mathrm{~B} / \mathrm{D}$ liquid produced was water infiltrating from a $12 \mathrm{ft}$ long perforation interval. To shut this zone off, a single nano-additive particulate gel was applied through coiled tubing. This treatment resulted in an increase in oil production to $1000 \mathrm{~B} / \mathrm{D}$ with just $1 \%$ water cut.

\subsection{Changqing Field, China}

Changqing Field is an oilfield located in the Ordos basin of China characterized by ultra-low permeability [31]. The field has been producing since 2008 but in 2016, the oil production decreased drastically while water production increased averaging $63.92 \%$. Polyacrylamide-based polymer microspheres were applied to four wells in the pilot zone to arrest this water cut. A three-stage treatment was adopted applying $800 \mathrm{~nm}, 300 \mathrm{~nm}$, and $100 \mathrm{~nm}$ initial diameters of PMs respectively for each stage. Given their small size, these PMs reached deeper areas of the formation sealing off high permeability channels. A total increase of 4609 tons in oil production was recorded following the treatment. 


\subsection{Cantarell Field, Mexico}

Cantarell field is the largest oil field in Mexico that started production from a highly cavernous carbonate reservoir in 1976 [98]. A combination of organically crosslinked polymer (OCP) consisting of acrylamide, t-butyl acrylate (PAtBA) covalently crosslinked with PEI and a rigid setting metal oxychloride material (RSM) were used to seal high permeability streaks in the reservoir. OCP was reported to be very convenient for field application and effective in water shut-off. With a design viscosity of less than $30 \mathrm{cP}$, it was easy to inject the polymer solution to the target zone before the onset of crosslinking. Because of the presence of PEI, OCP offered longer gelation periods and thermal stability up-to $191{ }^{\circ} \mathrm{C}[40,47]$. OCP proved more effective in controlling the vuggy porosity of the carbonate reservoir as compared to RSM which only had a near wellbore effect. In the four test wells observed, the water cut was significantly reduced thus prolonging the life of the already mature field. A water-cut log for test Well 4 showed a drastic drop in water production from $14 \%$ at start of polymer flooding to less than $2 \%$ over a period of three years.

\subsection{Dina Cretaceous Field, Colombia}

Dina Cretaceous field produces oil from a sandstone reservoir. Due to a decline in oil production, peripheral waterflooding was adopted to stimulate secondary recovery [11]. Though this treatment increased the production to 9850 BOPD from the highest record of $6500 \mathrm{BOPD}$, the field was soon highly water cut. Pre-cross-linked polymer gels were recommended for a pilot test to address the reservoir's vertical heterogeneity and enhance sweep efficiency. HPAM polymer crosslinked with chromium and aluminium was used. This polymer gel was injected in form of colloidal dispersions offering better injectivity and high RRF. The pilot test carried out between 2011 and 2015 encompassed four wells (DK-03, DK-04, DK-06, DK-32ST). Results from the first pilot well showed a significant reduction in water production and increase in oil production rate from 80 to $200 \mathrm{BOPD}$. The injection profile revealed improved contact of un-swept oil zones and effective selective sealing of high permeability water producing zones. With the technical and economic (every kilogram of the polymer gel produced an additional five barrels of oil) success of this pilot project, a full-field expansion was recommended.

Table 1. Summary of field properties for the case studies.

\begin{tabular}{|c|c|c|c|c|c|c|}
\hline Field [Ref] & Reservoir Type & $\mathrm{T}^{\circ} \mathrm{C}$ & Permeability & Polymer Used & $\begin{array}{c}\text { Volume } \\
\text { Injected (BBL) }\end{array}$ & Result of Treatment \\
\hline Heather [93] & $\begin{array}{c}\text { Brent Sandstone (Upper } \\
\text { zone @ 9500’ TVD and } \\
\text { lower zone } \\
@ 11,800^{\prime} \text { TVD) }\end{array}$ & $176^{\circ} \mathrm{C}$ & - & $\begin{array}{c}\text { Polymer }+ \\
\text { organic crosslinker }\end{array}$ & 1095 & $\begin{array}{l}\text { Complete water shut off } \\
\text { from upper Brent } \\
300 \mathrm{~B} / \mathrm{D} \text { of oil increase } \\
\text { and } 2290 \mathrm{~B} / \mathrm{D} \text { of } \\
\text { water reduced }\end{array}$ \\
\hline $\begin{array}{c}\text { Stat fjord } \\
\text { [94] }\end{array}$ & $\begin{array}{l}\text { Brent Sandstone (Upper } \\
\text { (Tarbert \& Ness } \\
\text { formation); and lower } \\
\text { Etive, Rannoch \& } \\
\text { Broom formations)) } \\
\text { @3100 TVD }\end{array}$ & $95^{\circ} \mathrm{C}$ & - & $\begin{array}{l}\text { Polymer } \\
\text { silicate gel }\end{array}$ & 1500 & $\begin{array}{l}84 \% \text { to } 68 \% \text { water } \\
\text { production reduced }\end{array}$ \\
\hline $\begin{array}{l}\text { Miller } \\
\text { [95] }\end{array}$ & $\begin{array}{l}\text { Sandstone alternating } \\
\text { with shale }\end{array}$ & $121^{\circ} \mathrm{C}$ & - & $\begin{array}{l}\text { PAM + AMPS + } \\
\text { Zirconium }\end{array}$ & 2340 & $\begin{array}{l}60 \% \text { reduction } \\
\text { in water cut } \\
150 \% \text { increase in } \\
\text { oil production }\end{array}$ \\
\hline $\begin{array}{c}\text { Southeast } \\
\text { Kuwait Field } \\
\text { [97] }\end{array}$ & Sandstone @5100’ TVD & $65^{\circ} \mathrm{C}$ & $744 \mathrm{mD}$ & $\begin{array}{l}\text { Nano-based } \\
\text { particulate gel }\end{array}$ & 20 & $\begin{array}{l}90 \% \text { to less than } 10 \% \\
\text { reduction in water } \\
\text { production } \\
\text { Increased oil production } \\
\text { to } 1000 \text { BOPD }\end{array}$ \\
\hline
\end{tabular}


Table 1. Cont.

\begin{tabular}{|c|c|c|c|c|c|c|}
\hline Field [Ref] & Reservoir Type & $\mathbf{T}^{\circ} \mathbf{C}$ & Permeability & Polymer Used & $\begin{array}{c}\text { Volume } \\
\text { Injected (BBL) }\end{array}$ & Result of Treatment \\
\hline $\begin{array}{c}\text { Changqing } \\
\text { [31] }\end{array}$ & $\begin{array}{l}\text { Unspecified formation } \\
\text { at } 8462^{\prime} \text { TVD }\end{array}$ & $70^{\circ} \mathrm{C}$ & $0.03-3 \mathrm{mD}$ & $\begin{array}{l}\text { Polyacrylamide- } \\
\text { based PMs }\end{array}$ & 30 tons & $\begin{array}{l}\text { Overall reduction in } \\
\text { water production and a } \\
\text { total increase of } \\
4609 \text { tonnes }\end{array}$ \\
\hline $\begin{array}{c}\text { Cantarell } \\
\text { [98] }\end{array}$ & $\begin{array}{l}\text { Vuggy Carbonate @ } \\
8265^{\prime}-10,700^{\prime} \text { MD }\end{array}$ & $93^{\circ} \mathrm{C}$ & $1 \mathrm{mD}-6 \mathrm{D}$ & PAM + PAtBA + PEI & 1195 & $\begin{array}{l}\text { Water-free oil produced. } \\
\text { Well1: } 1325 \mathrm{~B} / \mathrm{D} \\
\text { increase in } \\
\text { oil production }\end{array}$ \\
\hline $\begin{array}{c}\text { Dina } \\
\text { Cretaceous [11] }\end{array}$ & Sandstone & $67^{\circ} \mathrm{C}$ & $10-400 \mathrm{mD}$ & $\begin{array}{c}\text { HPAM + } \\
\text { Aluminium + } \\
\text { Chromium }\end{array}$ & 3.49 million & $\begin{array}{c}\text { Increased in oil } \\
\text { production rate from } 80 \\
\text { to } 200 \mathrm{BOPD}\end{array}$ \\
\hline
\end{tabular}

\section{Conclusions}

From this study, it is evident that polymer nanocomposites present an optimal solution to conformance problems in fields tending towards maturity. The incorporation of organic crosslinkers in conventional bulk hydrogels has exhibited outstanding gelation control in several studies both at laboratory and field scales. Furthermore, addition of various nanoparticles has demonstrated enhanced stability of crosslinked polymers at high temperature and high salinity conditions improving their applicability and performance in harsh reservoir conditions. Adoption of silica NPs in the polymer composites has been shown to tremendously increase the salinity tolerance of synthetic polymers particularly in the presence of divalent ions which are prevalent in formation water. Besides, by utilizing their hydrophilicity, the degradation of polymers is prevented ensuring long term stability downhole. Graphene has also been shown to be an excellent additive for amplified mechanical strength and magnified elasticity of polymer hybrids suitable for deep high-pressure reservoirs. Though not much has been reported on the application of metal-based NPs in hydrogels, the studies reviewed have exemplified their inherent potential for increased mechanical strength and stabilization of polymer hybrid structures. Moreover, using magnetic metal-based NPs offers environmental benefits by enhancing removal of polymers from produced water.

Author Contributions: The authors listed contributed substantially to the work reported in this review article. V.O. prepared the original draft. U.Y. reviewed and edited the manuscript before submission. All authors have read and agreed to the published version of the manuscript.

Funding: This research received no external funding.

Institutional Review Board Statement: Not applicable.

Informed Consent Statement: Not applicable.

Conflicts of Interest: The authors declare no conflict of interest.

\section{References}

1. Al-Hajri, S.; Mahmood, S.M.; Abdulelah, H.; Akbari, S. An Overview on Polymer Retention in Porous Media. Energies 2018, 11, 2751. [CrossRef]

2. Hongfu, F.; Yongjian, L.; Liying, Z.; Xiaofei, Z. The study on composition changes of heavy oils during steam stimulation processes. Fuel 2002, 81, 1733-1738. [CrossRef]

3. Sheng, J.; Leonhardt, B.; Al Azri, N.S. Status of Polymer-Flooding Technology. J. Can. Pet. Technol. 2015, 54, 116-126. [CrossRef]

4. Seright, R.; Lane, R.; Sydansk, R. A Strategy for Attacking Excess Water Production. SPE Prod. Facil. 2003, 18, 158-169. [CrossRef]

5. Kelland, M.A. Production Chemicals for the Oil and Gas Industry, 2nd ed.; CRC Press: Boca Raton, FL, USA, 2014.

6. Seright, R.; Brattekas, B. Water shutoff and conformance improvement: An introduction. Pet. Sci. 2021, 18, 450-478. [CrossRef]

7. Firozjaii, A.M.; Saghafi, H.R. Review on chemical enhanced oil recovery using polymer flooding: Fundamentals, experimental and numerical simulation. Petroleum 2020, 6, 115-122. [CrossRef]

8. Seright, R.S.; Seheult, J.M.; Talashek, T. Injectivity Characteristics of EOR Polymers. In Proceedings of the SPE Annual Technical Conference and Exhibition, Denver, CO, USA, 21-24 September 2008. 
9. Han, M.; Alshehri, A.J.; Krinis, D.; Lyngra, S. State-of-the-art of in-depth fluid diversion technology: Enhancing reservoir oil recovery by gel treatments. In Society of Petroleum Engineers-SPE Saudi Arabia Section Technical Symposium and Exhibition; Onepetro: Al-Khobar, Saudi Arabia, 2014; pp. 1-10.

10. Liu, Y.; Bai, B.; Wang, Y. Applied Technologies and Prospects of Conformance Control Treatments in China. Oil Gas Sci. Technol. Rev. d'IFP Energ. Nouv. 2010, 65, 859-878. [CrossRef]

11. Leon, J.M.; Izadi, M.; Castillo, A.; Zapata, J.F.; Chaparro, C.; Jimenez, J.; Vicente, S.E.; Castro, R. Use of Cross-Linked Polymer Systems to Improve Volumetric Sweep Efficiency and Alternative Full Field Development Strategy for a Mature Waterflooding Optimization Processes-Dina Cretaceous Field Case. In Proceedings of the SPE Improved Oil Recovery Conference, Tulsa, OK, USA, 14-18 April 2018.

12. Ma, L.; Luo, P.; He, Y.; Zhang, L.; Fan, Y.; Jiang, Z. Ultra-Stable Silica Nanoparticles as Nano-Plugging Additive for Shale Exploitation in Harsh Environments. Nanomaterials 2019, 9, 1683. [CrossRef] [PubMed]

13. Zaitoun, A.; Dupuis, G. Conformance Control Using SMG Microgels: Laboratory Evaluation and First Field Results. In Proceedings of the Society of Petroleum Engineers-SPE Europec Featured at 79th EAGE Conference and Exhibition, Paris, France, 12-15 June 2017; pp. 607-616.

14. Thrasher, D.; Nottingham, D.; Stechauner, B.; Ohms, D.; Stechauner, G.; Singh, P.K.; Angarita, M.L. Waterflood Sweep Improvement at Prudhoe Bay, Alaska. In Proceedings of the SPE Improved Oil Recovery Conference, Tulsa, OK, USA, 11-13 April 2016.

15. Long, Y.; Wang, Z.; Ding, H.; Geng, J.; Bai, B. Investigation and Characterization of a Robust Nanocomposite Preformed Particle Gel for Enhanced Oil Recovery. Energy Fuels 2019, 33, 5055-5066. [CrossRef]

16. Ali, J.A.; Kolo, K.; Manshad, A.K.; Mohammadi, A.H. Recent advances in application of nanotechnology in chemical enhanced oil recovery: Effects of nanoparticles on wettability alteration, interfacial tension reduction, and flooding. Egypt. J. Pet. 2018, 27, 1371-1383. [CrossRef]

17. Fathima, A.; Almohsin, A.; Michael, F.M.; Bataweel, M.; Alsharaeh, E.H. Polymer Nanocomposites for Water Shut Off ApplicationA Review. Mater. Res. Express 2018, 3, 032001. [CrossRef]

18. Negin, C.; Ali, S.; Xie, Q. Application of nanotechnology for enhancing oil recovery-A review. Petroleum 2016, 2, $324-333$. [CrossRef]

19. Seright, R.S. A Review of Gel Placement Concepts. Pet. Recover. Res. Cent. 1996, 96, 21.

20. Bai, B.; Zhou, J.; Yin, M. A comprehensive review of polyacrylamide polymer gels for conformance control. Pet. Explor. Dev. 2015, 42, 525-532. [CrossRef]

21. Shen, J.; Yan, B.; Li, T.; Long, Y.; Li, N.; Ye, M. Study on graphene-oxide-based polyacrylamide composite hydrogels. Compos. Part A Appl. Sci. Manuf. 2012, 43, 1476-1481. [CrossRef]

22. Cheraghian, G.; Hendraningrat, L. A review on applications of nanotechnology in the enhanced oil recovery part A: Effects of nanoparticles on interfacial tension. Int. Nano Lett. 2016, 6, 129-138. [CrossRef]

23. Giraldo, L.J.; Giraldo, M.A.; Llanos, S.; Maya, G.; Zabala, R.D.; Nassar, N.N.; Franco, C.A.; Alvarado, V.; Cortés, F.B. The effects of $\mathrm{SiO} 2$ nanoparticles on the thermal stability and rheological behavior of hydrolyzed polyacrylamide based polymeric solutions. J. Pet. Sci. Eng. 2017, 159, 841-852. [CrossRef]

24. Wever, D.; Picchioni, F.; Broekhuis, A. Polymers for enhanced oil recovery: A paradigm for structure-property relationship in aqueous solution. Prog. Polym. Sci. 2011, 36, 1558-1628. [CrossRef]

25. Ghriga, M.A.; Grassl, B.; Gareche, M.; Khodja, M.; Lebouachera, S.E.I.; Andreu, N.; Drouiche, N. Review of recent advances in polyethylenimine crosslinked polymer gels used for conformance control applications. Polym. Bull. 2019, 76, 6001-6029. [CrossRef]

26. Zhang, X.; Zhang, S.; Li, L.; Wu, R.; Liu, D.; Wu, J.; Wu, W. High-temperature-resistant polymer gel system with metal-organic mixed cross-linking agents. J. Appl. Polym. Sci. 2015, 132, 1-8. [CrossRef]

27. Lu, Y.; Aimetti, A.A.; Langer, R.; Gu, Z. Bioresponsive materials. Nat. Rev. Mater. 2017, 2, 16075. [CrossRef]

28. Schattling, P.; Jochum, F.D.; Theato, P. Multi-stimuli responsive polymers-the all-in-one talents. Polym. Chem. 2014, 5, 25-36. [CrossRef]

29. Sorbie, K. Polymer-Improved Oil Recovery; Springer Science and Business Media: Berlin, Germany, 2013.

30. Clarke, A.; Howe, A.; Mitchell, J.; Staniland, J.; Hawkes, L.; Leeper, K. Mechanism of anomalously increased oil displacement with aqueous viscoelastic polymer solutions. Soft Matter 2015, 11, 3536-3541. [CrossRef]

31. Zhu, D.; Bai, B.; Hou, J. Polymer Gel Systems for Water Management in High-Temperature Petroleum Reservoirs: A Chemical Review. Energy Fuels 2017, 31, 13063-13087. [CrossRef]

32. Maghzi, A.; Kharrat, R.; Mohebbi, A.; Ghazanfari, M. The impact of silica nanoparticles on the performance of polymer solution in presence of salts in polymer flooding for heavy oil recovery. Fuel 2014, 123, 123-132. [CrossRef]

33. Yeo, S.-D.; Kang, A.I.-S.; Kirant, E. Critical Polymer Concentrations of Polyethylene Solutions in Pentane. J. Chem. Eng. Data 2002, 47, 571-574. [CrossRef]

34. Haruna, M.A.; Pervaiz, S.; Hu, Z.; Nourafkan, E.; Wen, D. Improved rheology and high-temperature stability of hydrolyzed polyacrylamide using graphene oxide nanosheet. J. Appl. Polym. Sci. 2019, 136, 47582. [CrossRef] 
35. Zhang, J.; Lei, W.; Liu, D.; Wang, X. Synergistic influence from the hybridization of boron nitride and graphene oxide nanosheets on the thermal conductivity and mechanical properties of polymer nano composites. Compos. Sci. Technol. 2017, 151, 252-257. [CrossRef]

36. Michael, F.M.; Fathima, A.; Alyemni, E.; Jin, H.; Almohsin, A.; Alsharaeh, E.H.; Huang, J. Enhanced Polyacrylamide Polymer Gels Using Zirconium Hydroxide Nanoparticles for Water Shutoff at High Temperatures: Thermal and Rheological Investigations. Ind. Eng. Chem. Res. 2018, 57, 16347-16357. [CrossRef]

37. Nguyen, B.D.; Ngo, T.K.; Bui, T.H.; Pham, D.K.; Dinh, X.L.; Nguyen, P.T. The impact of graphene oxide particles on viscosity stabilization for diluted polymer solutions using in enhanced oil recovery at HTHP offshore reservoirs. Adv. Nat. Sci. Nanosci. Nanotechnol. 2014, 6, 015012. [CrossRef]

38. Kamal, M.S.; Sultan, A.; Al-Mubaiyedh, U.A.; Hussein, I.A. Review on Polymer Flooding: Rheology, Adsorption, Stability, and Field Applications of Various Polymer Systems. Polym. Rev. 2015, 55, 491-530. [CrossRef]

39. Zhu, D.; Wei, L.; Wang, B.; Feng, Y. Aqueous Hybrids of Silica Nanoparticles and Hydrophobically Associating Hydrolyzed Polyacrylamide Used for EOR in High-Temperature and High-Salinity Reservoirs. Energies 2014, 7, 3858-3871. [CrossRef]

40. ElKarsani, K.S.M.; Sultan, A.S.; Hussein, I.A.; Al-Muntasheri, G.A. Performance of PAM/PEI gel system for water shut-off in high temperature reservoirs: Laboratory study. J. Appl. Polym. Sci. 2015, 132, 1-10. [CrossRef]

41. Yuan, T.; Meng, J.; Hao, T.; Wang, Z.; Zhang, Y. A Scalable Method toward Superhydrophilic and Underwater Superoleophobic PVDF Membranes for Effective Oil/Water Emulsion Separation. ACS Appl. Mater. Interfaces 2015, 7, 14896-14904. [CrossRef]

42. Zhao, C.; Zhang, P.; Gu, Z.; Chen, L.; Yi, H.; Cao, Z.; Jin, J.; Liu, M.; Jiang, L. Superspreading-Based Fabrication of Asymmetric Porous PAA-g-PVDF Membranes for Efficient Water Flow Gating. Adv. Mater. Interfaces 2016, 3, 1600615. [CrossRef]

43. Abolhasani, M.M.; Naebe, M.; Shirvanimoghaddam, K.; Fashandi, H.; Khayyam, H.; Joordens, M.; Pipertzis, A.; Anwar, S.; Berger, R.; Floudas, G.; et al. Thermodynamic approach to tailor porosity in piezoelectric polymer fibers for application in nanogenerators. Nano Energy 2019, 62, 594-600. [CrossRef]

44. Yadav, U.S.; Kumar, H.; Mahto, V. Experimental investigation of partially hydrolyzed polyacrylamide-hexamine-pyrocatechol polymer gel for permeability modification. J. Sol-Gel Sci. Technol. 2020, 94, 335-346. [CrossRef]

45. Goudarzi, A.; Almohsin, A.; Varavei, A.; Taksaudom, P.; Hosseini, S.A.; Delshad, M.; Bai, B.; Sepehrnoori, K. New laboratory study and transport model implementation of microgels for conformance and mobility control purposes. Fuel 2017, 192, 158-168. [CrossRef]

46. Imqam, A.; Bai, B.; Delshad, M. Micro-particle gel transport performance through unconsolidated sandstone and its blocking to water flow during conformance control treatments. Fuel 2018, 231, 479-488. [CrossRef]

47. Magzoub, M.I.; Shamlooh, M.; Salehi, S.; Hussein, I.; Nasser, M.S. Gelation kinetics of PAM/PEI based drilling mud for lost circulation applications. J. Pet. Sci. Eng. 2021, 200, 108383. [CrossRef]

48. Amir, Z.J.B.; Said, I.M. In situ organically cross-linked polymer gel for high-temperature reservoir conformance control: A review. Polym. Adv. Technol. 2019, 30, 13-39. [CrossRef]

49. Alsaba, M.T.; Al Dushaishi, M.F.; Abbas, A.K. A comprehensive review of nanoparticles applications in the oil and gas industry. J. Pet. Explor. Prod. Technol. 2020, 10, 1389-1399. [CrossRef]

50. Peng, B.; Tang, J.; Luo, J.; Wang, P.; Ding, B.; Tam, K.C. Applications of nanotechnology in oil and gas industry: Progress and perspective. Can. J. Chem. Eng. 2017, 96, 91-100. [CrossRef]

51. Almohsin, A.M.; Bai, B.; Imqam, A.H.; Wei, M.; Kang, W.; Delshad, M.; Sepehrnoori, K. Transport of Nanogel through Porous Media and Its Resistance to Water Flow. In Proceedings of the SPE Improved Oil Recovery Symposium, Tulsa, OK, USA, 12-14 April 2014.

52. Bera, A.; Belhaj, H. Application of nanotechnology by means of nanoparticles and nanodispersions in oil recovery-A comprehensive review. J. Nat. Gas Sci. Eng. 2016, 34, 1284-1309. [CrossRef]

53. Karimi, A.; Fakhroueian, Z.; Bahramian, A.; Pour Khiabani, N.; Darabad, J.B.; Azin, R.; Arya, S. Wettability Alteration in Carbonates using Zirconium Oxide Nanofluids: EOR Implications. Energy Fuels 2012, 26, 1028-1036. [CrossRef]

54. Thoniyot, P.; Tan, M.J.; Karim, A.A.; Young, D.J.; Loh, X.J. Nanoparticle-Hydrogel Composites: Concept, Design, and Applications of These Promising, Multi-Functional Materials. Adv. Sci. 2015, 2, 1400010. [CrossRef]

55. Xu, B.; Li, H.; Wang, Y.; Zhang, G.; Zhang, Q. Nanocomposite hydrogels with high strength cross-linked by titania. RSC Adv. 2013, 3, 7233-7236. [CrossRef]

56. Shirvanimoghaddam, K.; Balaji, K.; Yadav, R.; Zabihi, O.; Ahmadi, M.; Adetunji, P.; Naebe, M. Balancing the toughness and strength in polypropylene composites. Compos. Part B Eng. 2021, 223, 109121. [CrossRef]

57. Huerta-Angeles, G.; Hishchak, K.; Strachota, A.; Strachota, B.; Slouf, M.; Matějka, L. Super-porous nanocomposite PNIPAm hydrogels reinforced with titania nanoparticles, displaying a very fast temperature response as well as pH-sensitivity. Eur. Polym. J. 2014, 59, 341-352. [CrossRef]

58. $\mathrm{Hu}, \mathrm{Y}$; $\mathrm{Zhou}, \mathrm{S}$.; $\mathrm{Wu}, \mathrm{L}$. Surface mechanical properties of transparent poly(methyl methacrylate)/zirconia nanocomposites prepared by in situ bulk polymerization. Polymer 2009, 50, 3609-3616. [CrossRef]

59. Jiang, H.; Zhang, G.; Feng, X.; Liu, H.; Li, F.; Wang, M.; Li, H. Room-temperature self-healing tough nanocomposite hydrogel crosslinked by zirconium hydroxide nanoparticles. Compos. Sci. Technol. 2017, 140, 54-62. [CrossRef]

60. Du, Y.; Li, D.; Liu, L.; Gai, G. Recent Achievements of Self-Healing Graphene/Polymer Composites. Polymers 2018, $10,114$. [CrossRef] 
61. Wang, L.; Long, Y.; Ding, H.; Geng, J.; Bai, B. Mechanically robust re-crosslinkable polymeric hydrogels for water management of void space conduits containing reservoirs. Chem. Eng. J. 2017, 317, 952-960. [CrossRef]

62. Almohsin, A.; Michal, F.; Alsharaeh, E.; Bataweel, M.; Krishnan, M. Self-Healing PAM Composite Hydrogel for Water Shutoff at High Temperatures: Thermal and Rheological Investigations. In Proceedings of the Society of Petroleum Engineers-SPE Gas and Oil Technology Showcase and Conference 2019, GOTS 2019, Dubai, United Arab Emirates, 21 October 2019.

63. Keishnan, M.R.; Michael, F.M.; Almohsin, A.M.; Alsharaeh, E.H. Thermal and Rheological Investigations on N,N'-Methylenebis Acrylamide Cross-Linked Polyacrylamide Nanocomposite Hydrogels for Water Shutoff Applications. In Proceedings of the Offshore Technology Conference Asia 2020, OTC 2020, Houston, TX, USA, 2-6 November 2020.

64. Ko, S.; Lee, H.; Huh, C. Efficient Removal of Enhanced-Oil-Recovery Polymer From Produced Water With Magnetic Nanoparticles and Regeneration/Reuse of Spent Particles. SPE Prod. Oper. 2017, 32, 374-381. [CrossRef]

65. Suleimanov, B.A.; Veliyev, E.F. Novel polymeric nanogel as diversion agent for enhanced oil recovery. Pet. Sci. Technol. 2017, 35, 319-326. [CrossRef]

66. Whitby, C.P.; Scales, P.; Grieser, F.; Healy, T.W.; Kirby, G.; Lewis, J.A.; Zukoski, C.F. PAA/PEO comb polymer effects on rheological properties and interparticle forces in aqueous silica suspensions. J. Colloid Interface Sci. 2003, 262, 274-281. [CrossRef]

67. Maurya, N.; Mandal, A. Studies on behavior of suspension of silica nanoparticle in aqueous polyacrylamide solution for application in enhanced oil recovery. Pet. Sci. Technol. 2016, 34, 429-436. [CrossRef]

68. Montoya, T.; Coral, D.; Franco, C.A.; Nassar, N.N.; Cortés, F.B. A Novel Solid-Liquid Equilibrium Model for Describing the Adsorption of Associating Asphaltene Molecules onto Solid Surfaces Based on the "Chemical Theory". Energy Fuels 2014, 28, 4963-4975. [CrossRef]

69. Zhao, X.; Zhang, Q.; Chen, D.; Lu, P. Enhanced Mechanical Properties of Graphene-Based Poly(vinyl alcohol) Composites. Macromolecules 2010, 43, 2357-2363. [CrossRef]

70. Zheng, C.; Cheng, Y.; Wei, Q.; Li, X.; Zhang, Z. Suspension of surface-modified nano-SiO 2 in partially hydrolyzed aqueous solution of polyacrylamide for enhanced oil recovery. Colloids Surf. A Physicochem. Eng. Asp. 2017, 524, 169-177. [CrossRef]

71. Dai, S.; Chen, Z.; Huang, Z. Synthesis and characterization of water-sensitive core-shell type microspheres for water shut-off in the oil field. Russ. J. Appl. Chem. 2017, 90, 310-323. [CrossRef]

72. Liu, Y.; Dai, C.; Wang, K.; Zou, C.; Gao, M.; Fang, Y.; Zhao, M.; Wu, Y.; You, Q. Study on a Novel Cross-Linked Polymer Gel Strengthened with Silica Nanoparticles. Energy Fuels 2017, 31, 9152-9161. [CrossRef]

73. Liu, Y.; Dai, C.L.; Wang, K.; Zhao, M.; Zhao, G.; Yang, S.; Yan, Z.; You, Q. New insights into the hydroquinone (HQ)hexamethylenetetramine (HMTA) gel system for water shut-off treatment in high temperature reservoirs. J. Ind. Eng. Chem. 2016, 35, 20-28. [CrossRef]

74. Chen, L.; Wang, J.; Yu, L.; Zhang, Q.; Fu, M.; Zhao, Z.; Zuo, J. Experimental Investigation on the Nanosilica-Reinforcing Polyacrylamide/Polyethylenimine Hydrogel for Water Shutoff Treatment. Energy Fuels 2018, 32, 6650-6656. [CrossRef]

75. Asadizadeh, S.; Ayatollahi, S.; Zarenezhad, B. Performance evaluation of a new nanocomposite polymer gel for water shutoff in petroleum reservoirs. J. Dispers. Sci. Technol. 2018, 40, 1479-1487. [CrossRef]

76. Nazir, M.S.; Kassim, M.H.M.; Mohapatra, L.; Gilani, M.A.; Raza, M.R.; Majeed, K. Characteristic Properties of Nanoclays and Characterization of Nanoparticulates and Nanocomposites. Magn. Waves 2016, 35-55. [CrossRef]

77. Cheraghian, G. Thermal Resistance and Application of Nanoclay on Polymer Flooding in Heavy Oil Recovery. Pet. Sci. Technol. 2015, 33, 1580-1586. [CrossRef]

78. Saghafi, H.R.; Naderifar, A.; Gerami, S.; Emadi, M.A. Improvement in thermo-chemical stability of nanocomposite preformed particle gels for conformance control in harsh oil reservoir conditions. Can. J. Chem. Eng. 2016, 94, 1880-1890. [CrossRef]

79. Pu, W.-F.; Yang, Y.; Yuan, C. Gelation performance of poly(ethylene imine) crosslinking polymer-layered silicate nanocomposite gel system for potential water-shutoff use in high-temperature reservoirs. J. Appl. Polym. Sci. 2016, 133. [CrossRef]

80. Singh, R.; Mahto, V.; Vuthaluru, H. Development of a novel fly ash-polyacrylamide nanocomposite gel system for improved recovery of oil from heterogeneous reservoir. J. Pet. Sci. Eng. 2018, 165, 325-331. [CrossRef]

81. Kennedy, J.R.; Kent, K.E.; Brown, J.R. Rheology of dispersions of xanthan gum, locust bean gum and mixed biopolymer gel with silicon dioxide nanoparticles. Mater. Sci. Eng. C 2015, 48, 347-353. [CrossRef] [PubMed]

82. Wang, X.; Zhi, L.; Müllen, K. Transparent, Conductive Graphene Electrodes for Dye-Sensitized Solar Cells. Nano Lett. 2008, 8 , 323-327. [CrossRef] [PubMed]

83. Fowler, J.D.; Allen, M.J.; Tung, V.; Yang, Y.; Kaner, R.B.; Weiller, B.H. Practical Chemical Sensors from Chemically Derived Graphene. ACS Nano 2009, 3, 301-306. [CrossRef]

84. Meyer, J.C.; Geim, A.K.; Katsnelson, M.I.; Novoselov, K.S.; Booth, T.J.; Roth, S. The structure of suspended graphene sheets. Nature 2007, 446, 60-63. [CrossRef] [PubMed]

85. Bai, H.; Li, C.; Wang, X.; Shi, G. On the Gelation of Graphene Oxide. J. Phys. Chem. C 2011, 115, 5545-5551. [CrossRef]

86. Alzari, V.; Nuvoli, D.; Scognamillo, S.; Piccinini, M.; Gioffredi, E.; Malucelli, G.; Marceddu, S.; Sechi, M.; Sanna, V.; Mariani, A. Graphene-containing thermoresponsive nanocomposite hydrogels of poly(N-isopropylacrylamide) prepared by frontal polymerization. J. Mater. Chem. 2011, 21, 8727-8733. [CrossRef]

87. Liu, R.; Liang, S.; Tang, X.-Z.; Yan, D.; Li, X.; Yu, Z.-Z. Tough and highly stretchable graphene oxide/polyacrylamide nanocomposite hydrogels. J. Mater. Chem. 2012, 22, 14160-14167. [CrossRef] 
88. Hou, G.; Yuan, X.; Han, P.; Lu, F.; Jiao, Z.; Diwu, P.; Liu, T.; Hou, J. Field Application of Nano Polymer Microspheres Profile Control: A Pilot Test in Ultra-Low Permeability Oil Reservoir. In Proceedings of the Society of Petroleum Engineers-SPE Asia Pacific Oil and Gas Conference and Exhibition 2020, APOG 2020, Online, 12-14 October 2021.

89. Almoshin, A.M.; Alsharaeh, E.; Fathima, A.; Bataweel, M. A Novel Polymer Nanocomposite Graphene Based Gel for High Temperature Water Shutoff Applications. In Proceedings of the Society of Petroleum Engineers-SPE Kingdom of Saudi Arabia Annual Technical Symposium and Exhibition 2018, SATS 2018, Dammam, Saudi Arabia, 23-26 April 2018.

90. Shakeri, A.; Nakhjiri, M.T.; Salehi, H.; Ghorbani, F.; Khankeshipour, N. Preparation of polymer-carbon nanotubes composite hydrogel and its application as forward osmosis draw agent. J. Water Process. Eng. 2018, 24, 42-48. [CrossRef]

91. Shirvanimoghaddam, K.; Abolhasani, M.M.; Li, Q.; Khayyam, H.; Naebe, M. Cheetah skin structure: A new approach for carbon-nano-patterning of carbon nanotubes. Compos. Part A Appl. Sci. Manuf. 2017, 95, 304-314. [CrossRef]

92. Wang, L.; Xu, H.; Gao, J.; Yao, J.; Zhang, Q. Recent progress in metal-organic frameworks-based hydrogels and aerogels and their applications. Coord. Chem. Rev. 2019, 398, 213016. [CrossRef]

93. Whitney, D.; Montgomery, D.; Hutchins, R. Water Shutoff in the North Sea: Testing a New Polymer Gel System in the Heather Field, UKCS Block 2/5. SPE Prod. Facil. 1996, 11, 108-112. [CrossRef]

94. Boreng, R.; Svendsen, O. A Successful Water shut off. A case study from the statfjord field. In SPE Production Operations Symposium; OnePetro: Richardson, TX, USA, 1997; pp. 9-15. [CrossRef]

95. Williams, G.; Morgan, J.; Wylde, J.; Frampton, H. Frampton. Successful Field Application of a New Selective Water Shut Off System. In Proceedings of the 16 th International Oil Field Chemistry Symposium, Geilo, Norway, 15 March 2006.

96. Morgan, J.; Gunn, A.; Fitch, G.; Frampton, H.; Harvey, R.; Thrasher, D.; Lane, R.; McClure, R.; Heier, K.; Kayser, C. Development and Deployment of a "Bullheadable" Chemical System for Selective Water shut off leaving Oil/Gas Production Unharmed. In Proceedings of the Abu Dhabi International Petroleum Exhibition and Conference, Abu Dhabi, United Arab Emirates, 13-16 October 2002.

97. Al-Ebrahim, A.E.; Al-Houti, N.; Al-Othman, M.; Hamad, A.-M.; Al-Mehanna, M.; Mubarak, A.; Al-Adwani, Y.; Mahmoud, W.; Hai, L.; Panga, M.; et al. A New Cost Effective and Reliable Water Shutoff System: Case Study in Kuwait. In Proceedings of the Abu Dhabi International Petroleum Exhibition \& Conference, Abu Dhabi, United Arab Emirates, 13-16 November 2017.

98. Deolarte, C.; Vasquez, J.E.; Soriano, J.E.; Santillan, A. Successful Combination of an Organically Crosslinked Polymer System and a Rigid-Setting Material for Conformance Control in Mexico. SPE Prod. Oper. 2009, 24, 522-529. [CrossRef] 